\title{
LA PICARESCA Y AMERICA EN LOS SIGLOS DE ORO
}

Un hecho un tanto sorprendente ha venido desde antiguo a llamar la atención de los especialistas en los Siglos de Oro españoles: si el Descubrimiento afectó profundamente — para bien o para mal- a la economía castellana del momento, su influencia parece haber sido, en cambio, muy lateral para los intereses de la literatura. Y un panorama semejante ha sido documentado por A. Tudisco para las letras del XVIII: «...los temas americanos no ocupan ni preocupan a lo; escritores españoles (del XVIII) tanto como era de esperarse» ${ }^{1}$.

Salvo casos como los de Fernández de Oviedo ${ }^{2}$, Quevedo ${ }^{3}$, Góngora ${ }^{4}$ y otros, la intelectualidad no puso sus ojos con atención en Indias, y muchas veces, si lo hizo, fue con un grado variable de crítica y rechazo. Si buscarnos géneros y cbras en que el impacto pueda ser estudiado plenamente, la epopeya tiene bien poca presencia de los acontecimientos americanos, fuera de una obra notable como La Araucana de Ercilla, y en el teatro sólo cabe señalar unas pocas que traten el tema por extenso, por ejemplo alguna y de tono menor de Lope y varias de Tirso. Los autores literarios nos dan la impresión de haber vivido en general bastante de espaldas a las Indias, embebidos sin duda en la realidad urgente de la vida peninsular, y en ellos se observa con frecuencia, dentro del escaso interés, más bien esa citada actitud de crítica o rechazo, de dis-

1 América en la literatura española del siglo XVIII. «Anuario de Estudios Americanos», Sevilla, 1954, vol. XI, págs. 565-585. La cita es de la pág. 565.

2 Historia general y natural de las Indias, edición de J. Pérez de Tudela Bueso. Madrid, 1959, II, pág. 191.

3 La fortuna con seso y la bora de todos, fantasía moral, así como también el soneto «Advertencia a España» y el «Túmulo a Colón».

4 El discurso contra los descubrimientos en la «Soledad Primera», vv. 401-466. 
tanciamiento moral respecto a ciertas consecuencias del Descubrimiento y la colonización. $Y$ en el caso de la novela picaresca, a la que vamos a dedicar estas páginas, encontramos también solamente algunas menciones y referencias, que son muchas menos de las que quizás cabría esperar, dado el relieve que hoy concedemos a aquellos acontecimientos. No se trata por supuesto sólo del hecho de que el primer libro picaresco aparecido en Indias, el de Concolorcorvo, se haga esperar hasta 1773. Más allá de esta circunstancia, que no deja de ser igualmente significativa, parece darse incluso una cierta incompatibilidad entre el género, $o$, si se prefiere, la figura del pícaro novelesco, y las andanzas por las Indias, un tema que conviene analicemos, si bien no de un modo exhaustivo, sí con cierto detenimiento.

Hoy la idea de que la picaresca es hija de la crisis económica surgida a raíz, como una motivación esencial, del Descubrimiento y la colonización ", es muy objetable. Como dice B. Bennassar ${ }^{\beta}$, es «completamente inexacto considerar la iniciación de un empobrecimiento duradero de las clases populi:res...; por el contrario, hasta los años 1570 se asiste a un enriquecimiento general» y «todavía los años 1578-1590 son buenos en muchas regiones». J. A. Maravall ha expresado un parecer semejante aunque en otros términos y más vinculados a nuestro tema: «La picaresca se suscitó en la fase en que la crisis del trabajo se barruntaba; maduró (uuncío todavía se pensaba que podía tener remedio y que de no procurarlo podía surgir una amenaza para los ricos; llegó a su fase final cuando estos últimos optaron por solucionar represivamente la jugada y mantuvieron una producción estacionłria, dejando a la intemperie a la población excedente, a esos desvalidos incapaces de cualquier tipo de discordancia que no fuera la nıera lamentación y que aceptaron vivir de limosna...» ${ }^{7}$. Las

5 Por ejemplo De Pedro, V.: América en las letras españolas del Sislo de Oro, Buenos Aires, 1954, págs. $238 \mathrm{~s}$.

6 La España del Siglo de Oro, Bercelona, 1983, pags. 209 y 211.

7 La literatura picaresca desde la perspectiva social (Siglos XVI y XVII). Madrid, 1986, pág. 183. 
fechas en que surge la picaresca literaria pueden inducir a engaño. Y sus causas son demasiado complejas crimo para que puedan ser reducidas a un esquema simplista, y autores como Américo Castro han señalado, por ejemplo, la relación entre la temática de la limpieza de sangre y la aversión al trabajo manual. El parasitismo social, que está en la base del fenómeno picaresco, tiene muy hondas raíces, mucho más allá de hechos como el Descubrimiento y sus consecuencias económicas, por influyentes que éstas fueran. Hoy cabe decir que el pícaro, con claros antecedentes en el Medioevo y con esta herencia todavía patente en el Lazarillo, es un tipo situado entre el concepto medieval del pobre como detentador de un derecho cristiano a la caridad y el concepto emergente, que terminará por imponerse en la sociedad moderna, del pobre como detentador de un derecho (cuando no una obligación) al traLajo. De ahí que pueda aprovecharse aún del cencepto tradicional del indigente y trate de huír de su etiquctación bajo el concepto nuevo, que lo forzaría a convertirse en asalariado estable. El pícaro, que se mueve en esa zona fronteriza, sabe que de algún modo tiene su existencia, o mejor, su supervivencia como indigente, asegurada bajo el amparo del viejo concepto del pobre, pero que además una situación económica de escasez de mano de obra le permite, cuando lo precisa, practicar trabajos más o menos inestables, en particular en cierta clase de servicios como mozo de muchos amos, sin que por ello pueda catalogársele como asalariado, ya que, además, muchas veces tales oficios valen sólo como «una salvaguardia a la picardía» ${ }^{8}$, es decir, para encubrir la vagancia. Esa escasez de mano de obra, que fue, por otra parte, un atractivo para la emigración foránea ${ }^{y}$, está perfectamente atestiguada, tanto a nivel rural como en las ciudades castellanas de cierta actividad manufacturera y, lo que nos importa más, en las aglomeraciones urbanas de índole más comercial, como es c’ caso de Se-

8 La expresión procede del cap. IX de la Segunda Parte de la Vida de Lazarillo de Tormes, edición de P. M. Piñero. Madrid, 1988, pág. 323.

9 Bennassar: La España del Siglo de Oro, págs. 97 y ss. 
villa. $\mathrm{Y}$, en última instancia, el pícaro siempre puede alistarse en el ejército, puesto que no sólo hay pícaros soldados, sino que existió una real picaresca cuartelera, como muestra el nutrido grupo de quienes desertaban para volver a inscribirse más de una vez y cobrar así reiteradamente la prima de enganche ${ }^{10}$. Pero el nuevo concepto del pobre al tiempo sitúa al pícaro, que forma parte de una fauna definible como parasitaria, en la esfera del «vago vicioso», cada vez más duramente denunciada y reprimida, sobre todo desde mediados del XVI ${ }^{11}$. El pícaro, por otra parte, y nos referimos ahora estrictamente al novelesco $y$, en consecuencia al tipo de individuo que parece poder representar, evita con cierto cuidado, inclu. so, como Rinconete y Cortadillo, aun en la complicidad de asesinos y matones, verse confundido con el malhechor, con el bandido. Por no hablar de la evolución marcadamente moralizante que atestiguan textos como el Guzmán de Alfaracbe - la Vida del escudero Marcos de Obregón y otros.

Entrando ya en nuestra materia, podemos comenzar por recordar unos cuantos datos relevantes. Mateo Alemán publica en 1604 su segunda parte del citado Guzmán de Alfarache en la que el protagonista se propone pasar a Indias para huir de su ama, tras robarle «una buena pella» de sus haberes ${ }^{12}$. En El celoso extremeño de 1613, el casi pícaro hidalgüelo del inicio marcha a América para hacer fortuna, cosa que también hace el Buscón don Pablos, con poco o ningún éxito, en 1626. Lázaro de Manzanares ya había prometido hacer lo propio en 1620 y Alonso, el Donado Hablador, según se nos cuenta en el capítulo octavo de la primera parte, lo había logrado en 1624. En cuanto al Píndaro de La varia fortuna del soldado Pindaro de Céspedes y Meneses (1626), se ha de recordar que él y su amigo se proponen el tal viaje en la parte 1.a, cap. XIV, y lo llevan a efecto algo después.

Pero en casi todos los casos enumerados la promesa del

10 Ibidem, pág. 66.

11 Ibidem, pág. 206.

12 Se cita por la edición de B. Brancaforte en Madrid, 1979: aquí vol. II, pág. 433. 
viaje del protagonista allende el mar queda en nada. Ni las segundas partes americanas del Buscón y del de Manzanares llegan a escribirse, ni el trapacero Guzmán acaba en Indias la dicha aventura. Píndaro y Silva permanecen $\in$ n tierra tras ser embrujados en su primer intento de embarcar. Marcos de Obregón, pícaro estrambótico y moralista donde los haya, quiere ir a Indias Occidentales, pero una plaga diezma la armada. También Estebanillo tiene un contratiempo (un temporal), con lo que es enviado de vuelta al puerto y queda finalmente en tierra, o, lo que es casi lo mismo, pone, como Guzmán, pies en polvorosa por algún puntillo con la justicia. Cuando como ocurre en la novelita de Cervantes, el héroe pasa a América, el episodio se nos narra del modo más sumario, aunque sin alcanzar la concisión del gran Quevedo, que supo reducir a tres palabras («y fuéme peor») ${ }^{\mathbf{1 3}}$ el periplo indiano de $\mathrm{Pa}$ blos. Sólo, como una de las interesantes excepciones de feliz arribada, Alonso el Donado llega a vivir una notable aventura en el nuevo continente, con un rápido enriquerimiento, pero tan fulminante casi como su inmediata ruina en México y su retorno de nuevo en la indigencia. $Y$ en este caso, como veremos, su estancia en Indias, si bien no se diferencia demasiado de cualquier otra estancia en una población de lia Península, hallamos además unos ribetes profundamente antipicarescos. En cuanto al caso menos conocido del soldado Píndaro de Céspedes y Meneses, debe decirse que los dos viajes a América de los protagonistas son narrados a vuelapluma y reciben menos atención que los detalles de los preparativos del viaje o de la misma navegación.

En otras novelas los viajeros indianos son personajes secundarios, normalmente ajenos a los afanes y metas picarescas de los protagonistas. Así el doctor Sagredo, amo de Marcos de Obregón, hidalgo de una pieza y mejor médico de su honra que de los padecimientos de su clientela, no es un pí-

13 Edición de A. Castro. Madrid, 1960, I, pás. 270. 
caro él mismo. Esto vale también para el comerciante del Entremés de «la castañera» ${ }^{14} \mathrm{o}$, en el «tranco» $\mathrm{X}$, la doña Tomasa del Diablo Cojuelo; dama dudosa y trapacera, si no pícara. Además, la última limita los términos del viaje a una vaga intención, que no a un propósito firme o a un embarque de hecho, en tanto que el personaje citado de Castillo Solórzano no detalla su aventura.

En varios de los relatos, pues, como decimos, el personaje central, $o$ alguno de sus adláteres, planea arribar o arriba efectivamente a Indias, pero, de modo casi invariable, su modesta epopeya es silenciada por el autor, vagamente prometida $o$ pronto truncada. El pícaro literario, mal que en ocasiones le pese, no suele ir a América o, si lo hace, no parece ocurrirle allí, salvo algunos pocos casos excepcionales, nada reseñable. Cabe dudar de si los autores de la picaresca se encuentran incómodos o ignorantes de aquella nueva realidad o si la atmósfera indiana, como hemos apuntado, tenía una cierta incompatibilidad con las metas del pícaro. A continuación y por seguir en esta línea en nuestro análisis, estudiaremos tanto las razones del pícaro para emigrar como las que lo invitaban a no hacerlo, ya fuera por fuerza o de grado.

Desde la perspectiva del pícaro no se puede negar que le fuera de sobra conocida, por ser tópica, la tama de la riqueza de las Indias en la España aúrea. Un «Potosí» o unas «Indias» venían a ser sinónimos de una fortuna incalculable. «El «rubio indiano» es, en palabras de Suárez de Figueroa ${ }^{15}$, la moneda de oro. La recurrencia del perulero rice o del criollo adinerado persistirá hasta nuestros días en las novelas y en el teatro. Al parecer, más que el afán de embarrarse, la obsesión del metal precioso sí invadió la literatura, muy a pesar c.el cierto olvido a que ésta en líneas generales confinó el nuevo continente. $\mathrm{El}$ oro americano y el del siglo literario no son el mismo, pero sí coinciden en un grado de interés, que indudablemente respondió más a una preocupación nácida de una

14 Castillo Solórzano, Alonso de: Aventuras del Bachiller Trapaza, edición de J. Joset. Madrid, 1986, pág. 249.

15 El Pasajero, edición de M.* I. López Bascuñana. Barcelona, 1988, vol. II, pág. 495. 
creciente crisis económica que de un auténtico apego a las novedades que las Indias suponían. En el mismo Donado bablador, Alonso, ante un personaje al que en Madrid todos felicitan, pregunta si «tráele algo la flota que ha venido de Indias» y en Sevilla contempla «las luminarias y alegría universal» por la arribada también de la flota ${ }^{16}$. $\mathrm{O}$, por citar otro ejemplo, recordemos el de ese ficticio, pero convincente, caballero linajudo de los Lodeñas en Las harpías en Madrid, que «venía tiquísimo» en la flota de América ${ }^{17}$.

El indiano y su oro, el intenso movimiento comercial, las más o menos sinceras exageraciones de los soldados que retornaban y la interesada propaganda de la Corona lograron crear en la imaginación del país un cuadro de riqueza exorbitante $y$, sobre todo, la creencia en que ésta era fácil de conseguir en las nuevas tierras. "De luengas vías luengas mentiras», reza el adagio. Y los testigos del esplendor americano, incluso si no tuvieron necesidad de exagerar las maravilla'; económicas de Ultramar, de su oro y de su plata, sí mintier on sobre la supuesta facilidad con que se obtenían. Todo ello hizo del Nuevo Mundo un lugar de notoria riqueza ilusoriamente disponible a los ojos de los que hacia él iban, y difícil de arrancar en opinión del que de allí retornaba, el indiano, ya fuera éste pobre o rico. Porque, como señala Miguel Herrero ${ }^{18}$, el venido de Indias era «guardoso» ${ }^{10} \mathrm{o}$, en voces aún más expresivas, «el hombre más miserable que crió naturaleza» ${ }^{20} \mathrm{O}$ poco pródigo de sus muchos dineros, si los tenía. Y la tal cortedad se acompañaba siempre, citamos a Herrero, de los encarecimientos de «los muchos trabajos que costaba el granjearlo y traerlo». Sobre estos afanes escribe G. Friederichi, partidario de la ambición como motor decisivo de la conquista, que

\footnotetext{
16 Se sita por la edición de la BAE, vol. XVIII, págs. 511a y 517a.

17 En la edición de la obra de Castillo Solórzano de P. Jauralde Pou. Madrid, 1985 pág. 135.

18 Ideas de los españoles del Siglo de Oro. Madrid, 1966.

19 El término se lee en La Garduña de Scuilla de Castillo Solórzano, edición de F. Ruiz Morcuende. Madrid, 1972, pág. 15.

20 La Garduña, pág. 31.
} 
"como esclavos de la afanosa codicia del oro dieron los españoles en América pruebas de su maravillosa tenacidad, de su celo incansable, que les llevó a realizar hazañas casi increibles» ${ }^{21}$. En cualquier caso, crónicas de viajes como los de Lope de Aguirre o Cabeza de Vaca confirman la ingratitud de la jornada americana. Fernández Navarrete ${ }^{22}$ insiste en la dureza de la andanza colonial, cuyo producto terminaba en gran parte limpiamente en mero provecho de extranjeros. Y Ferrández de Oviedo nos ofrece unas irónicas palabras que muestran a lo vivo y a todo color las penalidades indianas: "Y desta causa, aquellos primeros españoles que por acá vinieron, cuando tornaban a España algunos de los que venían en esta demanda del oro, si allá volvían, eran de la misma color dél; pero no con aquel lustre, sino hecho azamboas e de la color del azafrán o tericia; e tan enfermos, que luego, o desde a poco que allá tornaban, se morían, a causa de lo que acá habían padescido», para concluir que «se busca sl oro en estas partes, e topan más aína con lloro e muerte de los cuerpos, y en aventura mucha e peligro de las ánimas» ${ }^{23}$. Y por si fuera poco, un motivo tan real como literario como eran las tormentas atlánticas, no podía sino desanimar a parte al menos cle la caterva de delincuentes auténticos y aventureros de baja estofa $\mathrm{y}$, por supuesto, a nuestros héroes novelescos. Así, el soldado vagabundo Estebanillo nos relata doncisamente los sufrimientos de su desafortunado periplo marino: «En el poco tiempo que duró esta embarcación, no eché de menos la Mancha, pues por ser aguados mis camaradas y haberse todos mareado, fue siempre mi barriga caldero de torrezros y candiota de vino. Hallábame gordo y sucio, en blanco la bolsa, y en oscuro la camisa, los cabellos emplastados con pez y los calzories engomados con brea. Sobrevínonos una fiera tormenta, y

21 El carácter del descubrimiento y de la conquista de América. Trad. esp., México, 1973, pág. 337.

22 Conversación de monarquics y discursos políticos, BAE, XXV, pág. 479.

23 Las citas están tomadas de Enguita Utrilla, J. M.: «El oro de las Indias. Datos léxicos en la 'Historia general y natural' de Fernández de Oviedow, en F. Solano y' F. del Pino (eds.): América y la España del siglo XVI, Madrid, 1983, I, págs. 274 y 88. 
apareciéndosenos San Telmo después de pasada, nos volvió al puerto derrotados y sin flota ${ }^{24}$. En fin, que todø esto, de que había cumplida noticia en el rumor popular, no $\epsilon$ ra, según ya podemos intuir, precisamente un acicate para quienes, como el pícaro, tenían como meta una supervivencia razonable como vago errabundo con la básica condición del menor esfuerzo y una todavía menor tenacidad, con lo que la hipótesis del esperado y natural interés americano en un género como la picaresca comienza a debilitarse por razones lógicas. Para andar «vagando a la flor del berro», es decir a sus anchas, como el ideal picaresco en boca de Guzmán de Alfarache, no eran sin duda las Indias el lugar más apropiado.

Tales noticias, positivas y negativas, llegahan a una sociedad, la española, enferma de hidalguía ociosa y de afanada picaresca. Un fenómeno que tiene dos consecuencias sólo aparentemente inconexas. Una es la censura política y moral de los críticos de la codicia reinante y, por ello, del Descubrimiento: es el caso de don Francisco de Quevedo y de su enemigo, Luis de Góngora, de Luis Vélez de Guevara y de otros. Esta crítica es coincidente con la vinculación que establece el autor del Donado bablador entre la codicia y los negocios indianos de su protagonista, tal como recordaremos después. La segunda es que la mención del paso a Indias, dentro del relativo papel de éstas en todos los géneros, no llega a convertirse en un lugar común, como podríamos esperar tal vez ingenuamente, de la novela en general y, en particular, de la ficaresca, «con pícaro» o apicarada, y del teatro. Es cierto que en ocasiones también el pícaro buscará en América su fortuna o su refugio (su «remedio») ${ }^{25}$, quizás más lo segundo que lo primero, pero incluso en esos casos, dignos de estudiarse, hallaremos notas peculiares que apuntan a una innegable reserva.

24 Edición de J. Mille y Giménez. Madrid, 1946, I, pág. 195.

25 El término se lee en Cervantes, El celoso extremerio, edición de H. Sieber: Novelas ejempleres. Madrid, 1988, II, pár. 99. 
Que el pícaro real se embarcara no es sorprendente, a pesar de tantas reservas y dificultades, de las que tenemos en las propias novelas cierta información fidedigr:a. Así, entre los consejos que recibe el Lazarillo de Manzanáses está el de que «no fuese a Indias - porque le dije yo que mi natural me inclinaba a ellas-, porque hay allá cantidad de perdidos a que es causa valer de balde la comida y no haber menester trabajar para ella, y por esta causa son más que en España, y el que quiere aplicarse en ella halla lo que otros van a buscar a cllas» ${ }^{26}$, y Alonso nos lo reitera con conceptos muy semejantes, si bien con la mente puesta en su frustración: «No son las Indias para todos: tantos perdularios andan por allá como por España, quizás fiados en que la comida no cuesta dineros y a ninguno le falta...». Un ejemplo egregio de esto es el del «licenciado en desvergüenzas» Estebanillo, que entra como tripulante y soldado en un bajel de Nueva España con pasmosa facilidad $^{27}$. Que desde el principio mismo de la colonización americana esto era cierto es bien seguro. Y para ello contamos incluso con la evidencia de los propios viajes de Colón, cuyas naos no se dotaron, según documenta Alice Gould, de tripulaciones precisamente irreprochables ${ }^{28}$. No pocos de sus hombres tenían cuentas pendientes con la justicia y varios condenados a muerte indultados y algún que otro ladronzuelo vieron en su compañía el Nuevo Mundo. Años después, en 1517, a la letra del testimonio dado por Fernández Vargas, un tal Berrio empujó a doscientos marginados, «los más taberneros y

26 Cortés de Tolosa, Juan: Lazarillo de Manzenares, edición de M. Zugasti. Barcelona, 1990, pág. 186.

$27 \mathrm{Si}$ lo que sucede con los colonos parecía ser, cuando menos, ur. serie de trámites enfadosos, por difusos que fuesen, sin embargo era tarea fácil y haceder: para los soldados. Tal es la conjetura que apoya el texto de los Avisos de Barrionuevo iportado por Maravall (La literatura picaresca..., pág. 265), dondo se trata la partida de emigrantes tras tomar un uniforme. El ejemplo literario de Estebanillo abona la misma tesis. Y es lógico suponer que entre la soldadesca, como entre los marineros prontos a desertar, pudiera haber un crecido número de truhanes.

28 Nuevos datos sobre Colón y los descubridores. «Boletín de la Real Academia de Historia», 66, 3, Madrid, 1920, pág. 151. Ver también: Fernández Vargas, V.: El control señorial en España y la emigración a las Indias. Una aproximación al tema, en «América y la España del siglo XVI», II, págs. 27-38. 
algunos rufianes y vagabundos y gente holgazana, y los menos labradores y da con ellos... en la Casa de Contratación». Ante tal presión callejera de los «vagabundos», se les embarca apresuradamente para el Nuevo Continente ${ }^{29}$. Datos de un calibre expresivo que hacen insistir a Gould, autora ya citada, en la emigración de delincuentes a Indias, pues «van a tener más facilidades para pasar a América que los tan deseados campesinos».

De la escrupulosidad de las pruebas de sangre y de conducta que con el tiempo pudieran exigirse ${ }^{30}$ no debemos fiarnos demasiado, dada la común corrupción administrativa, que permitía incluso entrar en la nómina de los familiares de la Santa Inquisición a personajillos de lamentables historiales ${ }^{31}$. El paso de Mateo Alemán a México, lleno de irregularidades, es todo un ejemplo bien conocido y de un tipo que no debió ser nada infrecuente.

$\mathrm{Y}$, por citar un caso individual, que tampoco debía formar parte de las rarezas, sabemos que un tal Juan de Góngora, sevillano y barbero, pagó con una perla su pasaje y fue a morir a Panamá, donde dejó un completo ajuar picaresco: doceuas de joyas falsas, cartillas, coplas, etc. ${ }^{32}$ De que allá no todos iban por amor de establecerse nos hablan las quejas de Fernández de Oviedo sobre esta calaña de precarios colonos:

\footnotetext{
29 Fernández Vargas, V.: El control señorial..., pág. 37.

30 «España practicó una polftica emigratoria selectiva, dictando una seric de normas por las que se pretendla evitar que en las Indias se produjesen determinadas situaciones de conflicto, seneralmente confesionales.... (el subrayado es nuestro); Solano, F. de: Emigración andaluxa a las Indias durante el siglo XVI, en «América y la España del siglo XVI», II, pág. 40. El mismo autor se refiere luego a ala documentación exigida en aquellos momentos: garantías sobre las costumbres y solidez cristiana, que se verificaba sobre testimonios fehacientes, no sólo del pasajero sino de sus padres y abuelos, debiéndose demostrar que el emigrante posela una antigua raigambre cristiana. Garantlas éticas y religiosas, unidas al peso profesional» (págs. 40 s.). Solano estima que el $50 \%$ de las entradas era ilegal (pág. 41), sin contar con el hecho de que apuede que se padezcan lagunas en la documentación y qu: no se contabilicen determinados elementos en las listas oficiales: marinero, sequito de los funcionarios y de los religiosos» (idem). No hace falta decir que estas últimas categorlas eran muy propensas a incluir a nuestros escurridizos personajes picarescos.

31 Ver datos en Bennassar: La Epaña del Siglo de Oro, págs. 224 y ss.

32 Vila Vilar, E.: La documentación de abienes do difuntosw como fuente para la bistoria social hispanoamericana: Panamá a fines del siglo XVI, en el citado *América y la España del siglo XVI», II, pág. 271.
} 
«...Danse a la mercaduría o a las minas, o la pesquería de las perlas, e a otras cosas con que presto alleguen hacienda con que se vayan. $\mathrm{E}$ por tanto, ningunos o muy rarus son los que quieren ocuparse en sembrar pan o poner viñas, porque los más que por acá andan, tienen a esta tierra por madrastra» (subrayado nuestro) ${ }^{33}$.

Pero en bien de una apreciación justa importa, por supuesto, observar que la tal emigración no fue, ni podía serlo, en la realidad patrimonio de las gentes de mal vivir. Nobles y campesinos honrados pasaron el mar en busca de prosperidad y libertad. No es otra la mira de los labradores de la Rioja de los que nos habla Las Casas, los cuales, según él, sacrificarían sus bienes españoles por enrolarse para el Nuevo Mundo, «tierra libre y real» ${ }^{34}$. Alguna dama deshonrada, como la Diana de Lope de Vega ${ }^{35}$, pudo hacerlo, con o sin su caballero galán (el Celio de Lope), para huir de su suerte.

Cervantes, en $\mathrm{El}$ celoso extremeño, llama a las Indias «refugio y amparo de los desesperados de España» ${ }^{*}$, pues cualquier mejora de fortuna podía acaecer allí. El «poderoso caballero» resultaba ser un indiano y el español de Indias daba en volver con el don por delante, como dicen le ocurrió al hermano de la Santa Teresa de Jesús. Tantos bienes debieron ser conocidos de los pícaros. Como ejemplo literario, Alonso se doctoró de rico comerciante por México en la novela de 1624. F. Morales Padrón hace notar el «cambio social que la adquisición de riqueza permite realizar en el conquistador» ${ }^{87}$.

Pues bien, si el pícaro real, el buscavidas, no tiene reparo en embarcarse fiado en ese utópico maná, de cuyos necesalios sudores hay también noticia segura, en el tipo novelesco esta abstención o laguna es sospechosa y no es difícil de re-

33 I, 80 \&, citado también por Enquita Utrilla en El oro de las Indias..., «Ibldem», I, phe. 275.

34 Noticia recogida por Maravall: La literatura picaresca..., par. 263.

35 En Las fortunas de Diana, Novelas a Marcie Leonarda, edición de J. Barelle. Madrid, 1988, phr. 58.

36 Ver note 25.

37 América en la literatura española, «Atlóntida» 4, 23, 1966, pág. 486. 
iacionar también, aparte del temor al esfuerzo $\mathrm{v}$ las jornadas fatigosas, con la actitud de reserva o crítica de las capas intelectuales. Por supuesto, aunque queden lejos los espejismos utópicos americanos de Luis Vives y de Tomás Moro, tan pronto defraudados, no es vano recordar que hay ya un fondo moral, una reserva ética en las palabras de algunos de nuestros autores y, paradójicamente (pues revelan una conciencia menos moribunda de lo que cabe suponérsele a un truhán del tres al cuarto), también en las frases de los personajillos por ellos creados ${ }^{38}$. Sólo en algún que otro caso aislado, como hemos adelantado, hay una aventura indiana digna de reseñarse. En el de Alonso estamos ante un episodio de aparente relieve, pero en que, y no debe ser un azar, éste recibirá una decisiva lección, con el castigo de su avaricia, que es el grave pecado asociado por su autor a las Indias ${ }^{3 \cdot}$. Y, además, la estancia de Alonso en México es «antipícara»: se metamorfosea allí en negociante y sólo lo frena en su ascendente prosperidad millonaria una estrepitosa quiebra, como la que podía sufrir cualquier traficante o banquero asentado en las Gradas sevillanas. Su singular e imprevista fortuna parece responder al tópico del fácil enriquecimiento en las nuevas tierras («cosa no intenté, ni en mercaduría puse mano, que los dos tercios no hallase de provecho y ganancias). Pero su calda fulminante es como una sanción bíblica. No sólo, diríamos, su loca ambición, que le lleva a arriesgados negocios con la China, es la antítesis de la conducta habitual del pícaro a que la literatura nos tiene acostumbrados, sino que vemos como lo más natural su retorno a la miseria y a la cotidiana incertidumbre. Para el autor es un ejemplo más de tantos que «he visto ir a Indias y volver tan rotos que cuando salieron de su pa-

38 Menudean las alusiones a la codicia y tacaf́erla indianas en los textos aúreos, pero mís evidente, si menos repetida, es la referencia a la maldad asociada al continente descubierto. Hallamos ejemplon de ella en la Aericultura cristiona de J. de Pineda, Splamanca, 1589, II, pís. 137b, citado por Herrero en Ideas de los espatioles..., phs. 317. Véase asimismo, el Diablo cojuelo (edición de A. R. Ferníndez e I. Arellano, Madrid, 1988), págs. 138 y 188, donde el demokuelo alude a la mala catadura de las conclencias indianas.

39 Opinión que colncide con la de Esteban Gonźllez, vol. I, pág. 195. 
tria...». Y también en el Lazarillo de Manzanares, en sus últimas páginas, el protagonista se deja convencer fácilmente por su protector para entrar en negocios indianos, en que participa como socio y aun embarcándose con el ánimo de ayudar «en la administración y venta de las cosas que de España se le enviaban», es decir transformándose en un eficaz comerciante y olvidado, suponemos, de sus andanzas peninsulares. Aun sin el obsesivo empeño moralizante del autor del Alonso, Cortés de Tolosa redime a su Lázaro metamorfoseándolo sin embargo en traficante indiano, es decir haciéndolo renegar igualmente de su antigua condición.

Aunque sabemos que, salvo en casos como el de Mateo Alemán, no hay que trazar un paralelo entre la vida del autor y la de su criatura picaresca, merece la pena no obstante señalar que los propios escritores de varias de las obras citadas ${ }^{40}$, gente, sin duda, de mejor ley que sus personajes, no pudieron pasar a Indias o se enfrentaron con grandes obstáculos al intentarlo. El ejemplo de Cervantes, como el que da más nábulo a las conjeturas sobre lo que del Quijote habría sido de haber prosperado su pretensión emigratoria, resulta el más citado con lujo de memorial y de infeliz respuesta oficial. Del judío Mateo Alemán sabemos que por serlo se encaró con increíbles dificultades para embarcarse y, finalmente, tras dos intentonas en 1580 y 1607 , se hizo de una cédula falsa de pureza de sangre con la que él y los suyos pudicron emigrar, no sin esperar un año que se dilató la salida. Y se dice que también el autor de Los sueños quiso hacerlo sin llegar nunca a cumplir su deseo ${ }^{41}$. En cambio, precisamente del autor del Donado bablador, novela en que tan inusual relseve tiene el negocio indiano, no hay noticia alguna que lo acredite pasando a América.

$40 Y$ algunos de los autores no picarescos ni pícaros, tales como San Juan de la Cruz. El santo quiso ir a México pero enfermó y murió en 1591 durante los meses de espera. Sus miras no fueron, sin embargo, picarescas en absoluto sino evangelizadores, como cabe suponer y $V$. de Pedro sostiene en su obra ya citada en nota 5, págs. 277-281.

41 Según conjetura V. de Pedro: Ibidem, pág. 174. 
El personaje picaresco, cuya geografía es tan nutrida y variada, se siente atraído por las grandes urbes: Madrid, Sevilla, París, las italianas más renombradas... Cuando la historia del género avanza, de modo paralelo se hace más ambiciosá y variopinta su expansión geográfica. El continuo desplazamiento es connatural al pícaro, como si aceptara en su inconsciente la analogía bíblica entre la vida humana y el peregrinaje, pero sin duda más por su afán de buscavidas y por su necesidad de impunidad, así como, en lo que hace a sus auto1es, debido a las lógicas posibilidades de variedad que los desplazamientos les proporcionaban. Con las grandes ciudades, donde el individuo se confunde con la masa y sus oscuros negocios pasan desapercibidos entre el trasiego urbano, compiten otros lugares en los que el antihéroe picaresco puede disfrutar de un anonimato comparable al que le depara la gran aglomeración. Tal es el caso de las almadrabas de Conil y Vejer y de las tierras extranjeras. Las famosas pesquerías de atún del duque de Medina Sidonia, como una verdadera legión extranjera de los tiempos modernos, son «río vuelto» ${ }^{42}$, donde los apellidos y los respectivos pasados se olvidan.

Hay más: la muchedumbre ciudadana o pescadora protege al vividor, pero la villa también le proporciona lo que Bennassar llama «la familiaridad de los poderosos» ${ }^{43}$, un vínculo beneficioso para el pobre aspirante a criado de tinelo o a cortador de bolsas. Oigamos al semipícaro Marcos de Obre. gón: «(...) no era cordura salir de Madrid, adonde todo sobra, por ir a una aldea, donde todo falta; (...) ${ }^{44}$. En estos lugares parecía existir una riqueza concentrada en pocas marios que, psicológicamente ( $y$ en algún caso criminalmente), cl pillo podía apropiarse.

Y pareja virtud a la de las jábegas de Cádiz tienen la Corte y otras ciudades ricas y crecidas en habitantes, de las cua-

42 Así Pedro de León en su célebra Compendio de algunas experiencicis..., editado por $P$. Ilerrera Puga: Grandeza y miseria en Andalucía. Testimonio de una encrucijada histórica (1578-1616). Granada, 1981, pág. 79.

43 La España del Siglo de Oro, pág. 326.

44 Edición de S. Gili Gaya. Madrid, 1951, I, pág. 24. 
les, como bien se sabe, era en la época Sevilla una de las más atractivas por su trajín comercial e industrioso. No en vano el bogavante Garay, travieso pícaro de la Garduña, «andaba encubierto» en la gran capital del Betis comparada con el laberinto de Creta por Vélez de Guevara ${ }^{45}$. Es este un punto en que hay, a no dudarlo, coincidencia entre el pícaro literario y la realidad del tiempo, por más que en aquél esté lógicamente exagerado su permanente vagabundeo. Luis de Góngora llamó a Sevilla «Gran Babilonia de España» en un romance. Para Alonso, Sevilla es «madre de tantos extranjeros y archivo de las riquezas del mundo». La ciudad era ante todo la antesala de las Indias y en ella la tentación de la aventura americana debía ser especialmente recia para los espíritus emprendedores y animosos, así como también para los necesitados de un «remedio» frente a la adversidad económica o la justicia. Y la vida sevillana estaba tan estrechamente ligada al cordón marítimo con Indias que puede decir Guzmán, en cierta ocasión en que la flota se hacía esperar, que «la ciudad estaba muy apretada, cerradas las bolsas y nosotros abiertas las bocas, muriendo de hambre». El pícaro, aprovechando las migajas del negocio indiano las más veces por vía indirecta y retorcida, podía sufrir sin embargo en sus carnes también sin embarcarse sus altibajos y avatares. Los dichos lugares ofrecen al que A. A. Parker dio en llamar de manera poco matizada "delincuente» ${ }^{40}$, pero que, insistimos, lo es sólo en tono menor usualmente, ese envidiable anonimato vecino de la impunidad. Nadie tiene ahí por qué saber su nombre de pila ni conocer su historial delictivo. En la era de la Santa Hermandad resultaba, a no dudarlo, más fácil apresar al pillo que corría la posta que al timador emboscado entre el gentío de la Contratación o de las Gradas sevillanas o de la Puerta del Sol madrileña. No en vano, la agitada Madrid era para las «har. jías» de Castillo Solórzano «apacible golfo» donde medrar

45 El dieblo cojuelo, "Trancow, IX, par. 209.

46 Citado por Francis, A.: Picaresea, decadencia, bistoria. Aproximación a una realidad bistórico-litererio. Medrid, 1978 phe. 20. 
sin ser conocido. Mudando éllas el barrio tantas veces como estafas, se aseguran la discreción de sus transacciones. Y por supuesto no es sólo el pícaro laico o literario el que acude a estos lugares. En Sevilla recalan incluso los picaros de hábito talar, los numerosos «clérigos vagantes» del XVII, originarios de otros lugares del país y también del extranjero ${ }^{47}$. Eran efectivamente Sevilla y Madrid, como entre las ciudades españolas las más ricas de las grandes, las que antes y mejor atraían a los «vagamundos» de los que habla el «Informe de los Jurados de Sevilla a Felipe IV» que cita también Domínguez Ortiz ${ }^{48}$. Si la «bética Híspalis» favorecía a algunos con el oro propio y a muchos más con el ajeno, la Corte, ese «piélago que admite todo peje» ${ }^{49}$, invitaba a cambiar de estado, a amanecer noble montañés o mayorazgo. Las «harpías», más interesadas en estafas a gentes de alcurnia, acuden a Madrid; otros como Pablos o Guzmán, pobretes de menos humos, sientan sus reales en la puerta de las Indias. Pero lugares más lejanos sirvieron también de ventas manchegas para los que desearon, como el judezno Guzmán de Alfarache en Génova, ser armados caballeros de arrabal. Las Italias, en las que se mueve tan a sus anchas un Marcos de Obregón, fueron famosas por idéntica virtud porque, al decir de Alemán, el don «no hay hijo de remendón español que no le traiga».

Pues bien, si cualquiera de las dos vías reconocidas de ascenso social -ennoblecimiento más o menos ficticio o bien pesos ensayados - era ya aceptada, entonces América, que podía, como las urbes, favorecer ambas a los ojos de los desahuciados y proporcionar el anonimato y la vecindad de la riqueza, había de ser, al menos en teoría, un destino predilecto de éstos en la misma medida en que lo eran las metrópolis y las pesquerías. El de Alfarache, que se cree ya en posesión de

47 Dominguez Ortiz, A.: La Sevilla del siglo XVII, 3." edición, aHistoria de Sevillaw, Sevilla, 1984, pás. 228.

48 Orto y ocaso de Sevilla, 2.^ edición, Sevilla, 1974, paras. 112 ss.

49 La Garduria, edición citada, pár. 240. 
los dineros de su señora en el pasaje aludido, decide «buscar ruevo mundo» sin duda como un urgente «remedio», por usar el término utilizado por Cervantes en El celoso extremeño justamente para las Indias ${ }^{30}$ : «Ya juzgaba si fuese requisitoria cie Italia, ya si de mis acreedores en Castilla o :1 de mis nuevos hurtos no purgados». Para un pícaro versado en Madrid, en Sevilla y en casi toda Italia, como es Guzmán, el «mundo» puede llegar a quedársele pequeño en el horizonte de sus fechorías y el que le resta por conocer es América. El tipo de expedición picaresca, improvisada, que Guzmancillo planea, queda consignada en su «como quiera que fuese» y en su «dar conmigo» en lugar de algún otro verbo de viaje más agradable y organizado. No dice - nótese bien- querer hacer fortuna allá, puesto que pensaba agenciarse el haber ajeno antes de partir, por lo que sus planes son bien distintos de los de un Alonso o Lázaro de Manzanares, más próximos al mercantilismo común. Ajeno a los esplendores indianos, Guzmán huye simplemente de su última gran pillería por la vía más rápida imaginable en un lugar como Sevilla. Y conociéndolo como lo conocemos, podemos presumir que, al igual que hakía hecho en Almagro, en Milán y en Génov:a, si efectivamente hubiese arribado a puerto americano, hubiese dado en cambiarse el nombre por alguno más sonoro, de más alcurnia, y pretendido seguir con sus manejos. De los dos móviles teóricos del viaje transatlántico ninguno escoge o menciona el de Alfarache: tan sólo podemos suponerle, a tenor de otras ocasiones, un afán de medrar socialmente (de haber ido en efecto a Indias).

Además, en la obra de Alemán hallamos, aunque en este caso sea forzada por las circunstancias, otra propiedad común

So El texto de Cervantes es perfecto para corroborar esa impresión de América como otra parada, pero sobre todo como la última, por estar más a trasmano, de picaros y maleantes: Filipo de Cañizares, tras consumir su poca hacienda en España, Italia Flandes y Sevilla, por ese orden, aviéndose, pues, tan falto de dineros, y aun no con muchos amigos, se acogí al remedio a que otros muchos perdidos en aquella ciudad se acogen, que es el de pasarse a las Indias" (El celoso extremeño, edición y lugar citados). Aguilera, M.: América en los clésicos españoles, (Bogotá, 1952, pág. 27) atribuye estas palabras esencialmente al rencor de Cervantes contra las nuevas tierras. 
j las escasas aventuras de los pícaros en América: nuestros personajes no se proponen, como sí hicieron algunos autores de sus libros, dirigirse al nuevo continente por incima de todo cbstáculo. De otro modo, les resulta bien fácil mudar de propósito al primer revés de fortuna. Es éste un rasgo connatural al «vagamundo», una parte de su andante naturaleza $y$, por ello, puede más en él que la atracción indiana. Las rutas picarescas son intrincadas, ajenas a todo programa que no sea el de la huida precipitada. A lo que parece, las Indias no son, no pueden ser, entonces un lugar de especial relieve $y$, por tanto, de mayor atractivo, sino otra más de las estacione, de vagabunclaje, tal como sucede en la novelesca autobiografía de Estebanillo. Es más, los posibles controles de salida, el ser estrechos y restringidos los cauces para ir y no haber mil vías disponibles de partida, frente a los mil acomodos y direcciones de las viejas tierras europeas, acrecentaban los escollos y disuasiones. Podía haber obstáculos concretos por lo demás. Como ejemplo, nos basta el lacónico «mas no lo pude ígrar» del de Alfarache ${ }^{51}$ para conocer su mudanza, aunque a la frase sigan las poderosas razones que la han determinado (es encarcelado por su última fechoría).

Es más, no sólo no parece existir una atracción especial por el Nuevo Continente, sino que un azar puede decidir la vuelta del héroe. En el Mozo de muchos amos, el Donado Alonsc abandona fulminantemente su frustrada esperanza indiana y las Indias mismas en cuanto su nuevo capital se evápora, muere su amo y se ve en la más negra ruina: América no le ofrece gaiantía de recuperación de su fortuna y retorna a sus ajetreos peninsulares sin pensarlo más. El que en el galeón de regreso coincida con «innumerables indianos riquísimos» no será un „cicate para una nueva intentona. Un ejemplo aún más sintomático nos lo proporcionan las estancias de Píndaro y Silva en la Nueva España. Los dos jóvenes aventureros acuden a Ultramar para volver en «patacas» o pesos de oro unas prendas

51 Lugar citado ya en la nota 12. 
llevadas desde la península. Una vez cobrado el valor de la mercancía, los jóvenes esperan el barco que los vielva a Sanlúcar. La narración de la "aventura» de Indias queda en el cncarecimiento de las frutas americanas, cuyo conocimiento confiesa deber Céspedes al «docto Acosta y el Palentino». De suerte que dos bribones adoctrinados en la escuela del Patio de los Naranjos como son Silva y Píndaro no realizan en aquéllas tierras más que una transacción sencilla y legal casi impropia de ellos. El interés por las cosas de las tierras descubiertas es muy relativo. Hay algún caso excepcional, cual es el del relato de Espinel, donde se narran prodigios y se nos ofrecen datos que la crítica está acorde en que han sido extraiclos de los historiadores indianos en buena parte, pero en quc. como ya recordamos, no es el protagonista de la novela el viajero, sino su comparsa el Doctor Sagredo, lo que le resta importancia en nuestra opinión.

Cuando, como en El soldado Píndaro, los "perdidos» de que nos habla el memorable pasaje cervantino van al Nuevo Continente por un fuerte afán aventurero, alimentado por una slusión juvenil, el trayecto no concluye allí, sino que abarca ctras tierras: «Teníamos los dos muy conformes cieseos, anhelando por pasar a las Indias y dar al mundo (cumo si fuese España solamente) tres o cuatro rodeos» ${ }^{52}$. Si in éste, que es de los pocos ejemplares picarescos con un genuinc interés americano, la voluntad de cruzar el mar es decidida. también es, sin embargo, evidente la intención de ir más allá, de continuar viaje. En los demás, cuando aparece, lo que comprobamos es que América obra en el ánimo de los personajes como un destino final «a falta de otro». Así oímos decir de la Tomasa del Diablo Cojuelo que trataba «desengañada, de pasarse a las Indias" ${ }^{3}$.

La contingencia del viaje americano en la nente del «vagamundo» es, mutatis mutandis, la del mismo cpisodio en la

52 BAE XVIII, pág. 303a.

53 Edición citada, pág. 238. 
de los creadores de las obras que tratamos. Si el Nuevo Mundo es poco más, cuando lo es, que otra parada del camino - puesto que lo fundamental y lo que presta unidad al conjunto es el propio camino y el que lo recorre, el pícaro-, es, asimismo, apenas algo más que un episodio del libro. Tan es así que Cortés de Tolosa, Alemán y otros de los dichos ni siquiera envían a su criatura al otro lado del Atlántico, y Quevedo soslaya la peripecia ultramarina, por más que sea uno de los pilares de la trama picaresca la inclinación a la complejidad argumental sobre la base del encadenamiento episódico.

En cambio, si bien el occidente atlántico no fue la meta primordial de todos los delincuentes, sí encaja cn su afán de desplazamiento. Como indica J. Deleito y Piñuela en su obra La mala vida en la España de Felipe $I V^{54}$, «a la vida difícil (del pícaro) se unía el ansia de movilidad y variación, creado en las andanzas de Europa y Ultramar (...)», en esa, como él la llama, «existencia centrífuga» del Imperio Español. El conocimiento de los viajes ajenos pudo tener, en efecto, su parte en el mencionado ensanchamiento del universo conocido del aventurero picaresco.

Y es que el pícaro, más que buscar, huye. Huye de la ley social, de los exámenes de sangre, de la policía, de su pasado,... Siendo así habrá de importarnos más lo que podría hacerlo emigrar que lo que le invita a hacerlo; la España que lo margina y lo acosa más que las Indias que presuntamente pudieran atraerlo. Un pasaje de La vida y hechos de Estebanillo González dice: «Echaba mi barriga al sol (en la almadraba), daba paga general a mis soldados y me reía de ios puntos de honra y de los embelecos del pundonor». Esteban se burla y se aparta en las jábegas de Vejer de lo que tantos otros temieron o sufrieron (Buscón, Guzmán...), esto es, de la España de las probanzas maniáticas, de los códigos. El pícaro se siente ajeno a las coordenadas en que se desenvuelve su sociedad. Una situación bien distinta de aquellos honrados labradores rio-

54 Madrid, 1989, pág. 116. 
janos de Las Casas: estos piensan mejorar labránciose una hacienda en libertad, en tanto que los de la picardía optan por el puro lucro mercantil, si se embarcan, o por hacerse de las haciendas ajenas con el robo o el timo. Por lo mismo, el campesino que no pensaba en ir a Madrid o Sevilla, donde el asalariado por lo común brega en la miseria, sino en ganarse los lotes de tierras nuevas, nada tiene que ver con cl vividor trapacero o el «caballero de la capa parda» que busca indistintamente pero sobre todo la aglomeración de la ciudad.

Pero, además, no bastaba con tomar la decisión de pasarse a Indias. Junto a la larga espera en muchos casos, había un cauce oficial, con examen por las autoridades, al menos para quien pretendía detentar algún cargo. Tal es también una razón para que no todos los pícaros, que en hipótesis hubieran podido desear ir, o incluso los propios literatos que pudieran estar inclinados a ello, como fue el caso positivo de un Gutierre de Cetina, lleguen a pisar el Nuevo Mundo. El mismo Alonso, que embarcará de criado con el «alguacil mayor de Méjico», habrá de mostrar de modo más enfático de lo habitual sus credenciales y testimonios de presunta honradez, sin que sea suficiente la apreciativa mirada del futuro amo, que sí lo es en tantas otras ocasiones. En tanto que el pasaje de vuelta ni requiere de tantos miramientos ni toca a los magistrados concederlo, toda vez que la probanza de sangre y de calidades de decoro se hizo ya a la ida.

Por todo ello, parece claro que el pícaro literario suele a lo sumo mostrar interés por las Indias cuando ya ha visitado (y con frecuencia descartado por la mala fama dejada) otros destinos de vagabundeo más inmediatos $\mathrm{y}$, quizá, a la letra de nuestro razonamiento anterior, más acomodados a sus necesidades picarescas (Italia, Francia, partes no vistas de las Españas...) que los virreinatos de ultramar. En varios casos es tan débil su afán indiano (y el del autor) que no llega a vivir la prometida continuación en América, dándonos ía impresión de que se trata más bien de una argucia del narrador para acabar de un plumazo su obra: así sucede, como hemos visto, en 
los del Buscón y de Lazarillo de Manzanares y, con menos precisión, de Guzmán. En algunos otros pocos sucede el proyectado viaje, con la citada y no rara metamorfosis del pícaro en su antítesis y la consiguiente e inevitable lección moral. Pero es evidente que, si como dice el de Manzanares, «el ingenioso en España las tiene», el pícaro literario al menos no siente casi nunca la urgencia de mudarse a fatigosas tierras, por más que de allá le lleguen halagüeñas noticias. Y también porque de allá también venían noticias no tan halagüeñas. Así pues, el trabajo americano, tal como hemos rerordado, con todas sus compensaciones (esclavitud y abundancia general), presentaba un cariz durísimo. Ante una perspectiva como ésta cabe preguntarse si, en cambio, podía ser atractivo para el pícaro un trabajo asalariado estable en la península o una vida de sacrificios en América ${ }^{53}$. Pésimamente remunerado como es bien sabido y que con frecuencia daba a lo sumo para el pan (y no es metáfora) familiar, en «una economía en la que la gran masa de la población trabajadora tenía dificultades para sobrevivir únicamente con sus salarios, en tal medida que con harta frecuencia lo que ganaban durante medio año tenía que dar de sí para un año entero», en palabras de Maravall ${ }^{56}$, que aún se queda corto sin duda en sus cálculos. Y cabe preguntarse ahora también: si ya el pícaro en su tierra huía de caer en esa triste condición del famélico asalariado, ¿podía esforzarse por buscar fortuna en Indias, a costa de penalidades y riesgos, si tenía, por ejemplo, en el citado Arenal sevillano un perulero siempre a mano a quien esquilmar ladinamente y que traía sudada plata indiana para su provecho? ${ }^{87}$.

Pero es que el que profesaba la picardía era esencialmen.

55 Ver Maravall: La literalura picaresca..., pás. 264, donde se pone de relieve la diferencia esencial entre el indiano y el vividor aventurero en su visión de la economía.

56 Ibidem, págs. 183 y ss., para datos de la carestía. Dominguez Ortiz: La Sevilla del siglo XVII, pág. 113.

57 Es de notar que América no suele constar en los catálogos de lugares picarescos más citados: así en el del ventero del capltulo III del Quijote, en el que se lee en La ilustre fregona, cuando se nos da cuenta de las peregrinaciones de Carriazo (Novclas ejemplares, II, págs. 140-141) y en el romancillo que recoge S. Montoto en su obra Esquinas y conventos de Sevilla, 3." edición, Sevilla, 1991, pág. 54. 
te un holgazán contagiado de la general repugnancia por los cficios mecánicos de la sociedad española. Tan arraigado está en ellos el vicio de la ociosidad, que ni siquiera parecen pararse a considerar la penuria del trabajador a sueldo. Al Lazarillo de Juan de Luna le oímos decir tras ajustarse como escudero de siete damas que «aquel no era oficio trabajoso, de que huía como del diablo; porque siempre quiss más comer berzas y ajos sin trabajar, que capones y gallinas trabajando» ".

En sus andanzas errabundas, en esa geografía que el género expande de modo continuo, cualquier lugar podía ser bueno como escenario de la hazaña picaresca, $p \in$ ro había sin duda grados y no parece haber sido Indias un certro entre los que dieran más facilidades para el desarrollo de esa trayectoria vital. Es más, si entre los tan debatidos cimientos del género está la ética, con frecuencia en la forma de una lección moral a costa del pícaro, era aquí en el viejo mundo donde, por un lado, el autor conocía más profundamente los entresijos sociales que le servían de escenario moral y, por otro, era esta rieja sociedad el mejor caldo de cultivo para las peripecias de su protagonista, que, como pícaro, servía de reflejo, todo lo literariamente modelado que se desee, de esos vicios sociales que se quería señalar.

Los escritores de novelas picarescas son, salvo excepciones como las de los expatriados autores del Gregorio Guada$\tilde{n} a$, de Estebanillo González y de la Segunda Parte parisina del Lazarillo, hombres profundamente arraigades en la vida nacional y sin duda atentos observadores de sus avatares. El trasiego migratorio del pícaro puede inducirnos :! engaño. Pero Don Pablos tiene la conciencia de que «nunca mejora su estado quien muda solamente de lugar, y no de vida y costumbres», y esto es lo que expresa exactamente El pasajero de Suárez de Figueroa: «Así, los que discurren de tierra en tierra en vano se mudan, por llevar enfermo el ánimo y antojadiza la voluntad...». La coincidencia de ideas entre el libro picaresco y el

58 Edición ya citada de P. M. Piñero, pás. 357. 
libro moral de Figueroa es evidente. Y no es casualidad, en el punto que más nos interesa, que ni El Buscón ni el Lazarillo de Manzanares tengan la continuación prometida, que nos hubiera narrado, si esto era posible, las andanzas de uno y otro en el Nuevo Mundo. Es claro que no es posible ciemostrar, en el reino de la hipótesis, que Don Pablos se hubiera transformado también en un negociante como Alonso en El donado bablador. Pero habría ahí una contradicción que nos hubiese gustado saber cómo la hubiera resuelto Quevedo, puesto que en lo que toca a Lázaro su conversión en negociantc: está ya expresamente consignada en el traslado.

Por otra parte, si de modo, a un tiempo paradójico y sintomático, vale decir, tal y como hace Suárez de. Figueroa en $E l$ pasajero, que «las Indias déstos (entiéndase «los extranjeros») son nuestra España, de quien sacan tantos tesoros...», y si, en efecto, así era, cosa de la que caben pocas dudas al que conoce los estudios económicos actuales de aquellos siglos, podemos suponer que si a los genoveses, franceses $u$ holandeses convenía más explotar la riqueza indiana sin colonizarla, esto es, por intermedio de España, ¿qué decir entonces del holgazán vividor español, aún menos emprendedor que el acomodado europeo?

Aún más, las posibilidades de lograr un enriquecimiento «indiano» sin embarcarse nos las revela, por ejemplo, $\mathrm{La} V i$ llana de Getafe de Lope de Vega, pícara por sus procedimientos, aunque ajena al género, y que en esos años se dedica a idénticas empresas fraudulentas sin salir de la Villa y Corte. A la revelación sigue el análisis en pormenor del procedimiento realizado por Castillo Solórzano. En sus Harpias y en su Garduña vemos a las estafadoras fingirse enriquecidas en Indias para justificar una posición social ficticia con la que granjearse lo ajeno ${ }^{5 \theta}$. Con tal procedimiento el intento de sustraerse a la propia (mala) fama y al linaje se complica sobremanera, perfeccionándose así el embeleco.

59 Sobre tal treta ver Maravall: La literatura picaresca..., pág. 265. 
Se crea así la imagen del falso indiano, hallazgo estupendo de la inventiva picaresca, pero que suponemos con sólidas bases reales, y que permitía, sin moverse de la Península y sin fatigas, adquirir todas las supuestas ventajas del que regresaba tras afanarse en Indias. Y mientras los bachilleres trapaza y las harpías madrileñas vuelven de las Américas sin haber ido allí, los sufridos colonos y soldados retratados por Fernández de Oviedo vuelven «rotos» ${ }^{\infty}$ a la patria, si es que sobreviven a la fiebre aurífera y a otras enfermedades menos preciosas. En fin, para concluir y sin que, como advertimos al inicio de estas páginas, haya estado en nuestro ánimo el hacer un análisis exhaustivo del tema y sin el recurso a todos los textos disponibles, creemos haber mostrado con argumentos de peso que en lo tocante a la aventura indiana el pícaro literario no parece ser un estricto reflejo del maleante y aventurero de la realidad, que sí acudió en buen número a la empresa americana. El pícaro de las novelas, posiblemente dentro del marco del frecuente e innegable despego de los intelectuales, apenas toma las Indias como una meta, renuncia, sí lo hace, con extrema facilidad o, en todo caso, se transforma en ellas en un antipícaro, en su contrafigura. Hemos hablado, incluso, un tanto provocativamente, de una relativa incompatibilidad entre la picaresca y el negocio indiano. Su caldo de cultivo estaba en la vieja Europa, sobre todo en la zona de influencia española y en especial en las ciudades de la Península. La plata y el oro americanos no fueron un atractivo suficiente para estas criaturas de ficción, que prefieren desenvolverse en los zocos urbanos, al amparo de un fácil anonimato y en que en último extremo podían beneficiarse del trasiego de aquel maná sin someterse en cambio a las fatigas que iban emparejadas con su logro en las nuevas tierras.

\section{Máximo Brioso Sánchez HÉctor Brioso Santos}

60 Sobre esta figura véase García Lorenzo, L.: «Será razón que llore y que nol cante». El amargo adiós del soldado Alonso de Ercilla, elı el libro ya citado América y la España del siglo XVI, I, págs. 373-380. 